Historic, Archive Document

Do not assume content reflects current scientific knowledge, policies, or practices. 


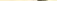




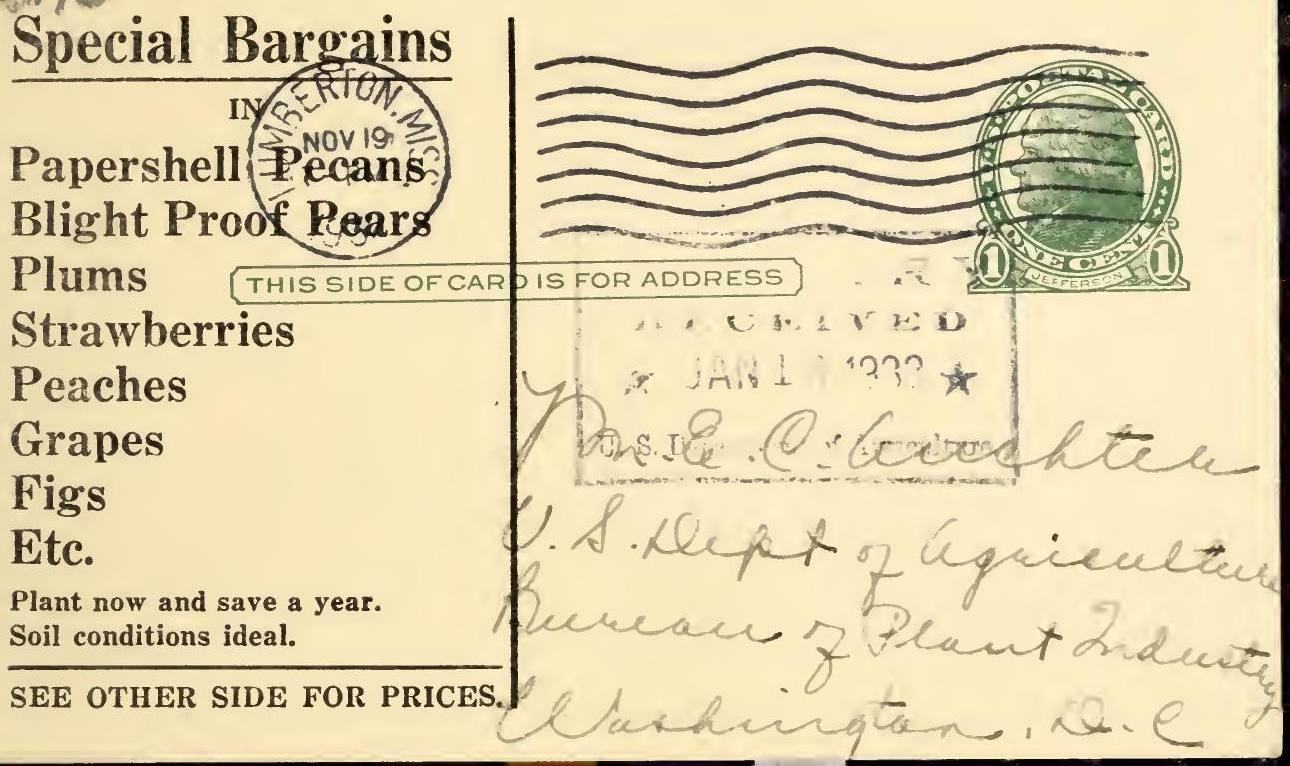




\section{PECAN and FRUIT TREE BARGAINS}

PLANT NOW AND SAVE A YEAR!

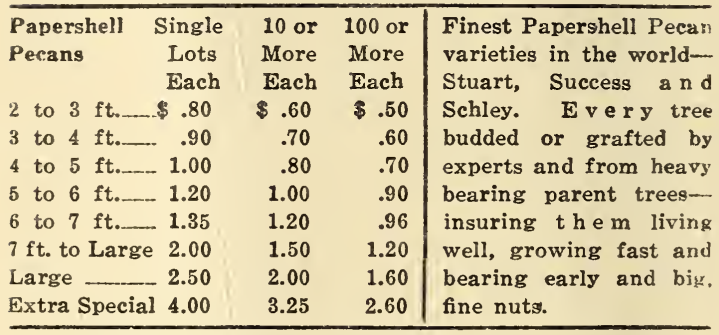

\section{FINEST FRUIT TREES-OUR OWN BEST SELECTION}

$\begin{array}{llllll} & \text { Peaches } & \text { Apples } & \text { Pears } & \text { Figs } & \text { Plums } \\ 3 \text { to } 4 \mathrm{ft} . & .25 & .25 & .25 & .30 & .25 \\ 4 \text { to } 5 \mathrm{ft} . \ldots & .35 & .35 & .35 & .35 & .35 \\ \text { Youngberries } & \text { 25c; (10 or more) } & 20 \mathrm{c} ;(100 \text { or more }) \text { 10c } \\ \text { Grapes } & \text { (1-yr.) 20c; (2-yr.) } & 25 \mathrm{c} ;(100 \text { or more) } 10 \mathrm{c}\end{array}$

Very fine Extra Special Blight Proof Pineapple Sand pear trees $\$ 1.00$ each-ready to bear. Free planting instructions.

Soil conditions are fine for planting pecan and fruit trees now because of recent rains. Trees you plant now will bear a year earlier than if you wait until next season. They will also live well, grow fast and bear early.

We guarantee prompt shipment and extra fine trees selected by experts. If No. 2 trees are desired-write for special prices and free catalogue.

RUSH YOUR ORDER-We guarantee satisfaction.

\section{BASS PECAN COMPANY}

"The Largest Pecan Growers in the World" LUMBERTON, MISS. 